\title{
Extreme climatic events: examples from the alpine region
}

\author{
Martin Beniston \\ Department of Geosciences, University of Fribourg, Switzerland
}

\begin{abstract}
This paper provides a general overview of climatic extremes, how they may be defined and what they represent both in statistical and in physical terms, as well as the impacts they are capable of generating. A particular case study, namely the heat wave that affected many parts of Europe from June-August 2003, will be discussed in some detail. The final part of the paper will investigate, on the basis of regional climate model simulations, the manner in which such events may change in the future under enhanced radiative forcing resulting from anthropogenic emissions of greenhouse gases. Many of the examples shown here originate in the alpine region of Europe that is very sensitive to a number of forms of extreme weather and has a high density and quality of data that make such studies possible.
\end{abstract}

\section{INTRODUCTION}

If climate continues to warm during the course of the $21^{\text {st }}$ century as suggested by the assessment reports of the Intergovernmental Panel on Climate Change (IPCC, 2001), it can be expected that extreme events such as heat waves, heavy precipitation, and wind storms will also increase, because the thermal energy that drives many atmospheric processes will be enhanced. Although this intuitive reasoning does have a physical basis, a clear demonstration that extremes have increased conjointly with the rise in mean global temperatures over the last 100-150 years cannot be made unequivocally, primarily because they are rare events that cannot necessarily be related in a statisticallymeaningful manner to changes in mean climatic conditions.

Public awareness to extreme weather hazards has risen sharply in recent years, in part because of instant media attention that serves to emphasize the catastrophic nature of floods, droughts, storms, and heat waves or cold spells. There is also a general perception that the number of extreme events has increased in the past few decades, based on statistics from the insurance sector as shown in Figure 1 (from Munich Re, 2002). These insurance statistics highlight the fact that, with the exception of earthquakes, climate-related hazards are those that take the heaviest toll on human life and exert among the highest damage costs. In the second half of the $20^{\text {th }}$ century, there have been 71 "billion-dollar events" resulting from earthquakes, but more than 170 events with similar costs related to climatic extremes, in particular windstorms (tropical cyclones and mid-latitude winter storms), floods, droughts and heat-waves.

There is thus an obvious incentive for the research community as well as the public and private sectors to focus on research related to extreme climatic events and the possible shifts in their frequency and intensity as climate changes in the course of the $21^{\text {st }}$ century. However, closer interpretation of the elements of Figure 1 shows that most of the increase in damage costs resulting from extreme climatic events is related to higher population densities in risk-prone areas than in past decades and a corresponding rise in insured infrastructure, rather than to an increase in the number of events themselves (Swiss Re, 2003).

There is no single definition of what constitutes an extreme event. Extremes can be quantified inter alia on the basis of:

- how rare they are, which involves notions of frequency of occurrence; this is the definition that the Intergovernmental Panel on Climate Change has adopted (IPCC, 2001), whereby an extreme is referred to as occurring below the $10^{\text {th }}$ percentile or above the $90^{\text {th }}$ percentile of a particular statistical distribution of temperature, precipitation, pressure, etc.

- how intense they are, which involves notions of threshold exceedance; the intensity of an event has a direct bearing on the associated human and economic damage costs, and can be related to heat waves, excessive wind velocities, or to both ends of the "precipitation spectrum" that can lead to droughts on the one hand and floods on the other;

- the impacts that may emerge from a particular event or set of events, that will also determine the costs for socioeconomic and environmental sectors that are related to extremes; impacts-based definitions of extremes are complex 
because in many instances, many damaging natural hazards can be triggered in the absence of an intense or rare climatic event.

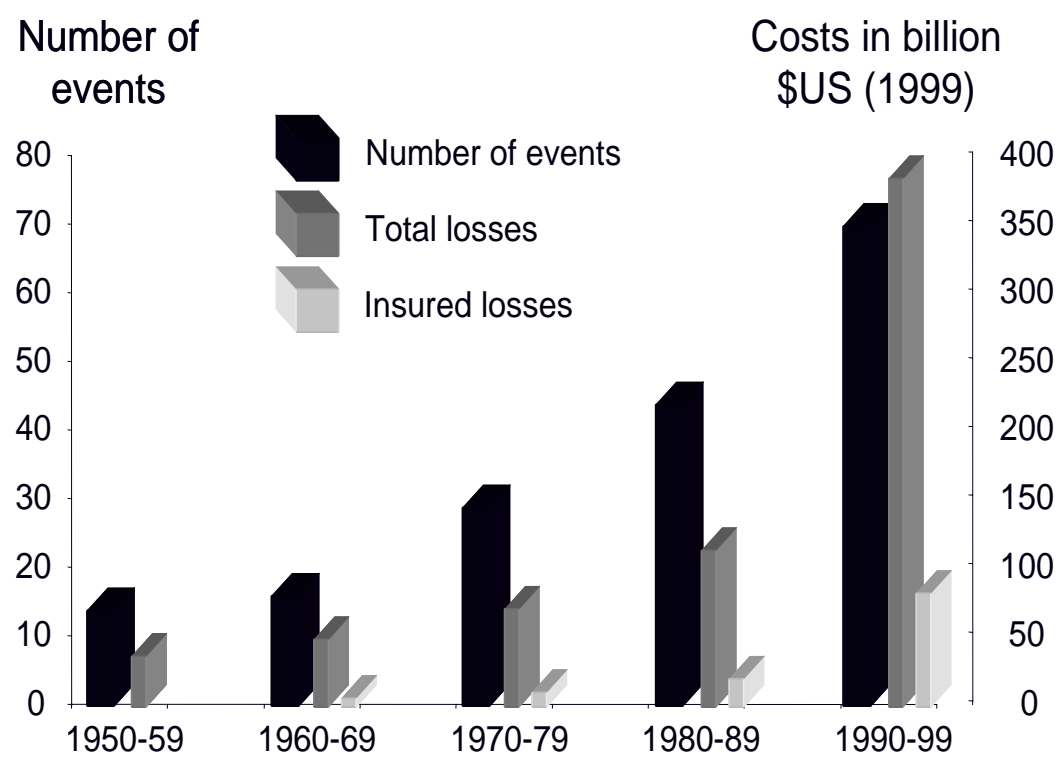

Figure 1. Number of extreme climate-related events, and the total and insured costs resulting from climate-related events in the second half of the $20^{\text {th }}$ century (From: Munich Re, 2002).

It is thus clear that none of these definitions on their own are entirely satisfactory, however, and each definition corresponds to a particular situation but cannot necessarily be applied in a universal context.

Understanding the mechanisms underlying various forms of climatic extremes is of interest to assess of the manner in which they may evolve in the future, under changing climatic conditions. A better understanding can in turn allow improvements in the ability to quantify the costs associated with natural climate-related hazards and thereby provide the basis for strategies to adapt to climatic change from an economic point of view.

\section{EXTREME EVENTS IN THE ALPINE REGION IN THE COURSE OF THE $20^{\mathrm{TH}}$ CENTURY}

Heat waves are generally believed to increase when average temperatures are on the rise, and this represents one instance where a link between changing means and extremes may be more obvious than for other variables such as precipitation.

A rise in the mean of temperature as given by the shift toward the right of the vertical arrows in Figure 2, would lead in the upper graph to a symmetrical shift in the probability density function (PDF) of temperature, with the same increase of extreme temperatures at the high end of the distribution (e.g., "heat waves") as there is a decrease at the low end of the PDF (e.g., "cold spells"), as indicated by the shaded areas. However, the change in mean temperature can also be accompanied by a shift in the skewness and/or the kurtosis of the distribution, yielding the profile in the lower part of Figure 2. Here, although the increase in mean temperature is lower than in the upper graph, the asymmetry of the curve yields a disproportionate rise in the upper temperature extremes with respect to the change in mean.

Over the course of the $20^{\text {th }}$ century in the alpine area, observations suggest that there has been a shift in the PDFs of both minimum and maximum temperatures, between the coldest part of the century (1901-1910) and the warmest part (1991-2000), as exemplified in Figure 3 for Basel, located at $317 \mathrm{~m}$ above sea level. The increase in average winter minimum temperatures is $2.2^{\circ} \mathrm{C}$ between the two periods. The number of days below freezing has decreased by half, from $26 \%$ to $13 \%$ of the winter season, while the number of warm winter nights (above $10^{\circ} \mathrm{C}$ ) has increased by a factor of 3 , from 2.5 to 8 days per winter. 

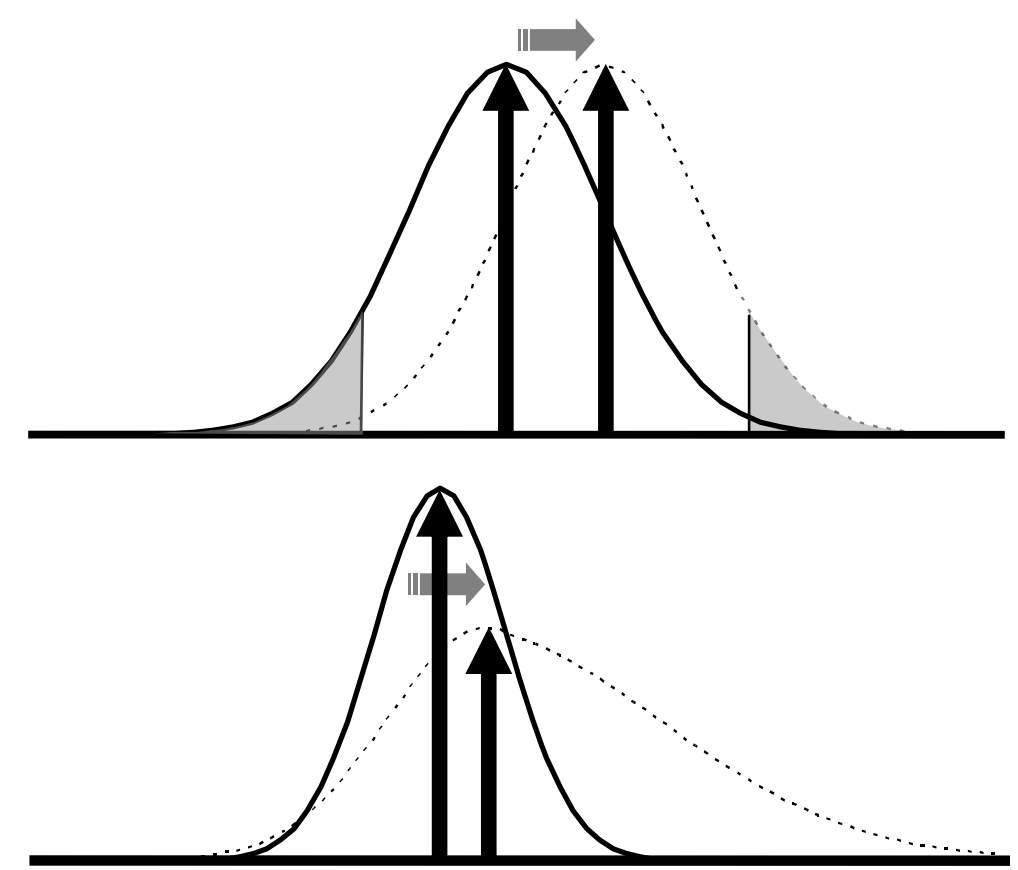

Figure 2. Illustrative examples of possible shifts in the probability density function of an atmospheric variable such as temperature. Upper: a symmetrical shift in the entire distribution; lower: an asymmetric shift with a change in both the skewness and the kurtosis of the distribution.

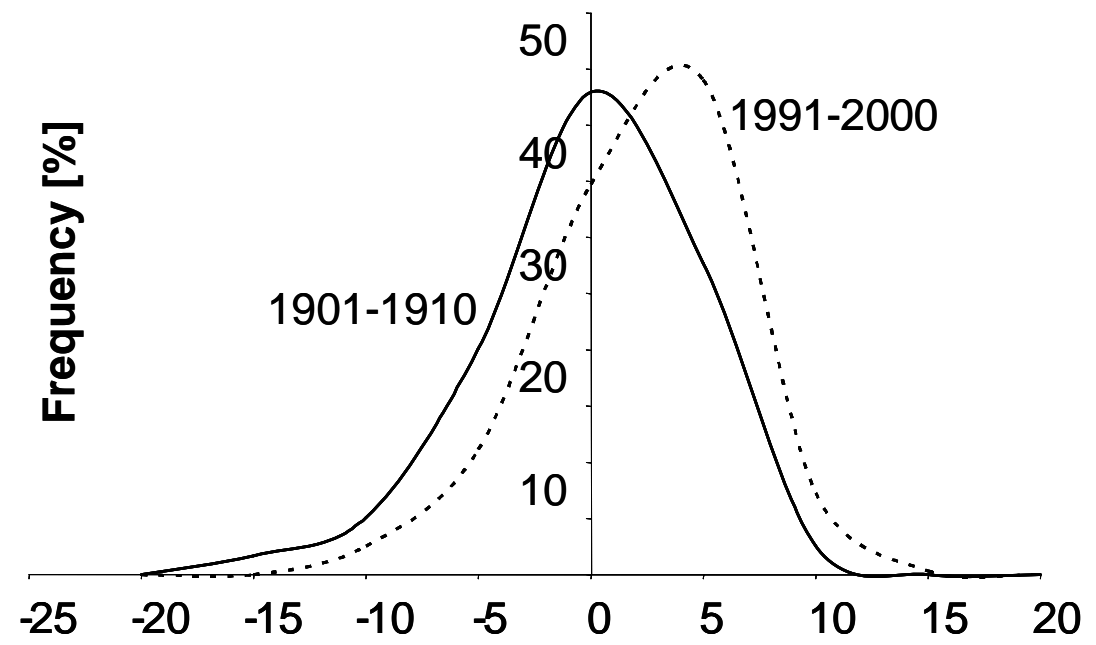

Figure 3. Shifts in the probability density function (PDF) of mean annual maximum temperatures at Basel between the coldest (1901-1910) and warmest (1991-2000) periods of the $20^{\text {th }}$ century.

When analyzing threshold exceedance such as the number of days with maximum temperatures above $30^{\circ} \mathrm{C}$ in $\mathrm{Basel}$, there is a correlation of 0.65 between mean annual maximum temperatures and threshold exceedance; this correlation rises to 0.90 when comparing the number of days exceeding $30^{\circ} \mathrm{C}$ with mean summer maximum temperatures (June, July, and August averages). This is logical in the sense that heat waves will generally occur during the summer, whereas on an annual basis, a cold winter may well be followed by a very warm summer, leading to moderate annual temperatures and thus a more tenuous link with threshold exceedance. Similar conclusions can be reached for most measurement sites at low elevations in Switzerland.

Other forms of extremes that cause considerable economic damage and, in many cases, loss of life include heavy precipitation events and winter storms. Heavy precipitation has increased significantly in the last quarter of the $20^{\text {th }}$ century in parts of the alpine region, although there is no clear and direct link to the observed rate of warming in the Alps that has accelerated in the last quarter of the $20^{\text {th }}$ century. Winter storms of the intensity of the December 1999 Lothar event are still extremely rare occurrences and cannot be linked in any statistically-meaningful manner to long- 
term global warming. This is principally because intense storms are generated in the Atlantic or the Mediterranean and their characteristics when they impact upon the alpine countries have little to do with local or regional temperature and moisture conditions in the Alps themselves.

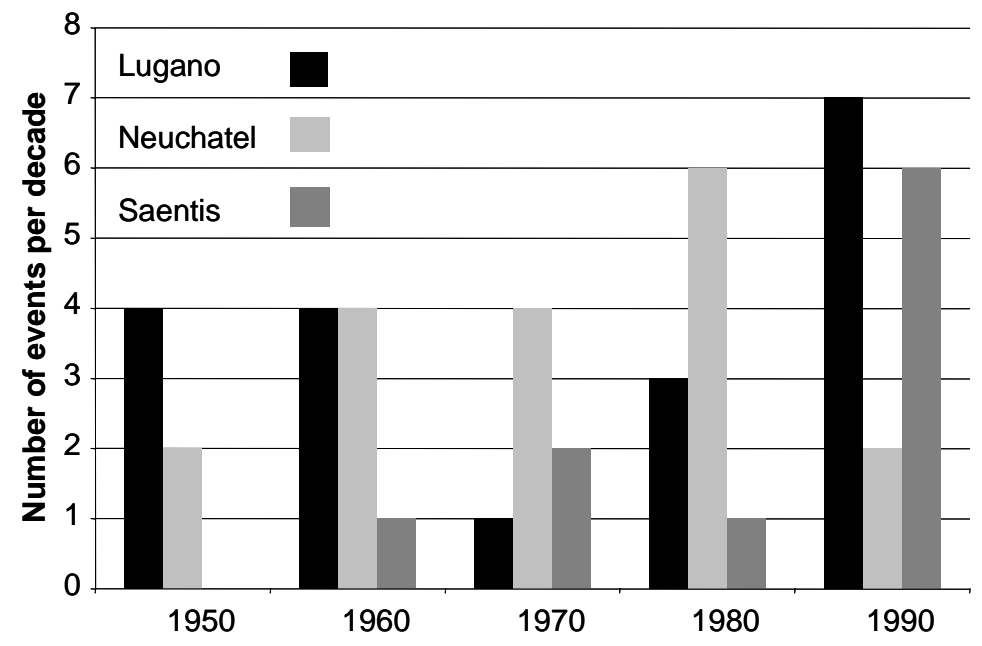

Figure 4. Number of extreme precipitation events exceeding thresholds of $100 \mathrm{~mm} /$ day in Lugano and Säntis, and $50 \mathrm{~mm} / \mathrm{day}$ in Neuchâtel on a decadal basis for the last 5 decades of the $20^{\text {th }}$ century. These thresholds represent roughly $4-\sigma$ events in terms of precipitation intensity.

Figure 4 shows the behavior of extreme precipitation events based on selected thresholds in Lugano (south of the Alps), Neuchâtel (north of the Alps), and Säntis (within the alpine domain at an elevation of $2500 \mathrm{~m}$ above sea level). The thresholds for Lugano and Säntis are $100 \mathrm{~mm} /$ day, and for Neuchâtel $50 \mathrm{~mm} /$ day, which are close to the respective 4- $\sigma$ levels of precipitation intensity The graph shows that the number of events during the second half of the $20^{\text {th }}$ century reached its maximum in Neuchâtel in the 1980s, and at Lugano and Säntis in the 1990s.

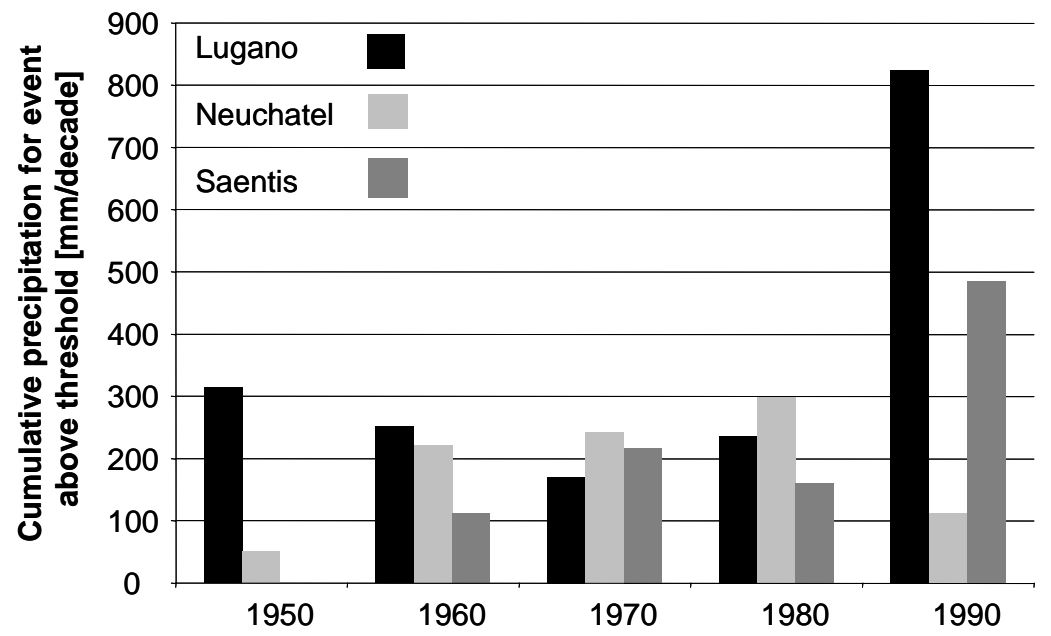

Figure 5. Cumulative precipitation for extreme events beyond the $100 \mathrm{~mm} /$ day threshold at Lugano and Säntis, and $50 \mathrm{~mm} /$ day in Neuchâtel for the last 5 decades of the $20^{\text {th }}$ century.

The sharpest increase is at Säntis where the threshold is exceeded 6 times in the 1990s compared to two or less occurrences per decade prior to the 1990s. In terms of the total amount of precipitation associated with these extremes, Figure 5 confirms the trends already seen in the number of events (Figure 4), where a three-fold increase in cumulated water amounts from the 1980s to the 1990s for the sites in the Alps and south of the Alps is observed; Neuchâtel on the other hand exhibits a decrease in total precipitation that is linked to the reduction in the number of events. At and above $100 \mathrm{~mm} /$ day, the potential for flooding and enhanced erosion is high, especially in exposed mountain terrain, as has 
been reflected in the high costs associated with the Brig catastrophe (September, 1993), the floods of Lake Maggiore in the falls of 1993 and 2000, and the devastating landslides and mudslides in the vicinity of the Simplon Pass (Gondo, October 2000), for example. Attempting to link these events to average warming trends, either on an annual basis or on the basis of the temperatures that prevail during the specific extreme precipitation event is difficult, because there is not necessarily any direct relationship between a given level of temperature at a particular location, and complex physical processes that are an aggregate of numerous mechanisms taking place at various spatial scales.

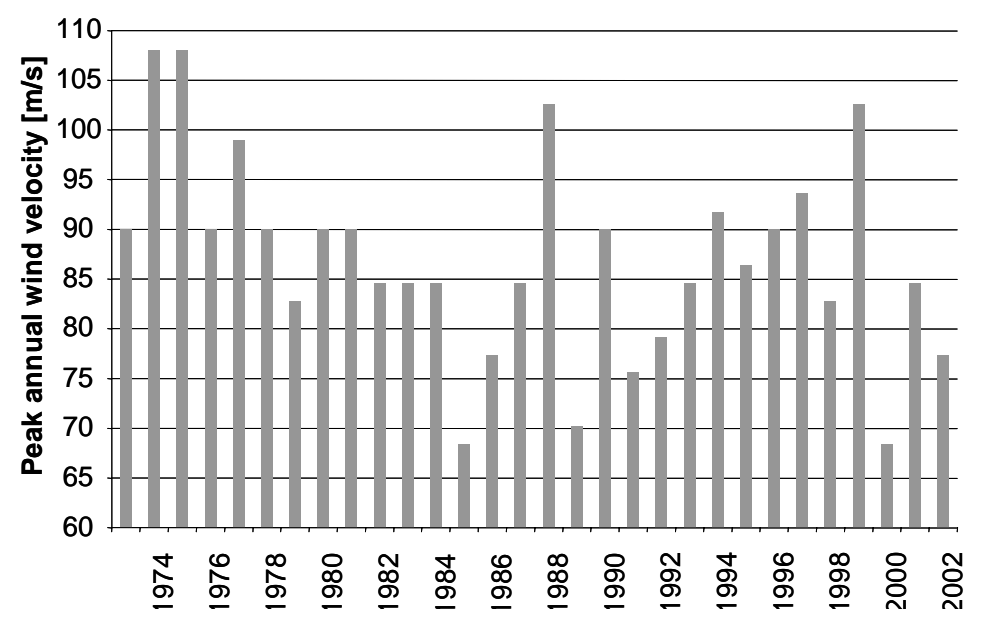

Figure 6. Annual peak wind velocities at La Dôle (western Switzerland, 1,690 m above sea-level) for the period 1973-2002.

In terms of extreme wind storms, the relationship between these events and warming trends is even more difficult to establish; strong storms are either generated over the Atlantic, or are associated with föhn-type flows over the Alps, and as such have very little to do with local climatic conditions over the Alpine domain. As shown in Figure 6, there are no trends apparent in terms of peak wind velocities recorded during each year of the last 30 years of the $20^{\text {th }}$ century at La Dôle, a summit in the Jura Mountains close to Geneva with an elevation higher than $1600 \mathrm{~m}$ above sea level. This site is exposed in such a manner that it intercepts westerly flows with little interference from any topography that may be located upstream of the wind in France. The record is rather short but nevertheless highlights the fact that there is no significant increase in extreme wind velocities in relation to the increase in mean annual temperatures of over $1^{\circ} \mathrm{C}$ that were recorded during this period at La Dôle.

Loss of life and economic damage resulting from strong wind storms, that generally occur during the winter in western Europe and the alpine area, can be significant (e.g., Ulbrich et al., 2000). The December 1999 Lothar storm resulted in uprooted or damaged trees equivalent to more than 4 times the annual felling rate in certain Swiss cantons (BUWAL, 2000), and damage to infrastructure that exceeded USD 1 billion in Switzerland alone and over USD 20 billion in the countries affected by the winter storm from France to central Europe, according to SwissRe (2003). Current 20-year return periods of wind velocities associated with winter storms are in the range $30-75 \mathrm{~m} / \mathrm{s}$, according to the altitude and the latitude of the site.

\subsection{A particular case: the 2003 heat wave and its impacts on Switzerland}

The record heat wave that affected many parts of Europe during the course of summer 2003 has been seen by many as a "shape of things to come", reflecting the extremes of temperature that summers are projected to have in the later decades of the $21^{\text {st }}$ century (Beniston, 2004; Schär et al., 2004). The heat wave resulted in absolute maximum temperature records exceeding for the first time in many locations in France, Germany, the United Kingdom, and Swizerland records that had stood since the 1940s and early 1950s, according to the information supplied by national weather agencies and highlighted in the annual report of the World Meteorological Organization (WMO, 2003).

Figure 7 illustrates the annual values of summer Tmax (JJA Tmax, i.e., the average of daily maximum temperatures recorded in June, July, and August) from 1901-2003 at Basel, Switzerland. The 2003 event stands out as a "climatic surprise", in the sense that it is the first time that average JJA Tmax in Basel has exceeded the $27^{\circ} \mathrm{C}$ threshold since 1952 , the $28^{\circ} \mathrm{C}$ threshold since 1947 , and the $29^{\circ} \mathrm{C}$ for the first time in this century-long record. The 2003 heat wave comes at the end of a 40-year period during which summers were markedly cooler than the warm summers of the mid$20^{\text {th }}$ century. Positive Tmax anomalies in Basel exceeded $6^{\circ} \mathrm{C}$. 


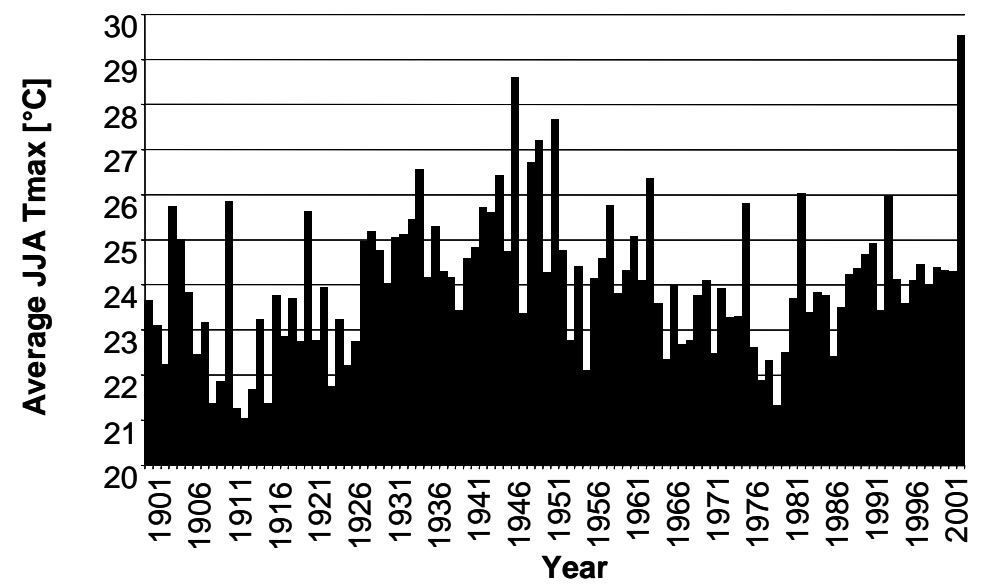

Figure 7. Summer (JJA) maximum temperatures recorded at Basel, Switzerland, from 1901-2003.

Within the European Union project PRUDENCE (Christensen et al., 2002), a suite of regional climate models have been applied to the investigation of climatic change over Europe for the last 30 years of the $21^{\text {st }}$ century, enabling inter alia an insight into possible changes in the extremes of temperature by 2100 . The HIRHAM4 regional climate model (RCM) of the Danish Meteorological Institute (Christensen et al., 1998) is one such model whose results correspond well with those of the other RCMs used in PRUDENCE. Furthermore, simulations of the reference climatic period 1961-1990 has shown that HIRHAM4 exhibits skill in reproducing contemporary climate, thereby providing some confidence as to its capability for simulating the characteristics of temperatures in the future.

The RCM results mapped over Europe for maximum temperatures and threshold excess have implications for the future course of extreme events such as the increase of heat waves and the reduction in cold spells and frost days. According to the baseline used, the very definition of a heat wave could change in a future, systematically-warmer climate, compared today. The climate of southern Spain, for example, that is currently characterized by temperatures exceeding $30^{\circ} \mathrm{C}$ for about 60 days per year on average may in the future experience over 150 days or more, i.e., close to half the year. Under such circumstances, the notion of heat wave loses some of its value when a rare or exceptional feature of today's climate becomes commonplace in tomorrow's climate. Figure 8 shows the shift in JJA Tmax between the 19611990 reference period and 2071-2100 for the RCM grid-point closest to Basel.

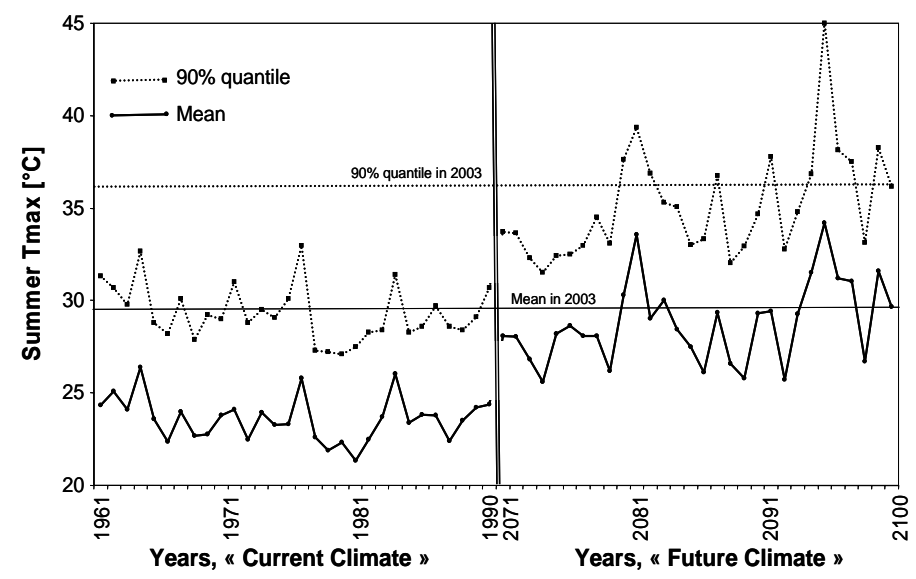

Figure 8. Changes in mean and $90 \%$ quantile of summer (JJA) maximum temperatures in Basel, Switzerland between contemporary (1961-1990) and future (2071-2100) climates. The level of 2003 temperatures is illustrated for comparison purposes.

Figure 9 illustrates the Gaussian fits to the JJA Tmax data the contemporary (curve A) and future climates (curve B); the 2071-2100 period is accompanied by a change in the variance of the distribution, which is a feature that has been observed in other studies (Katz and Brown, 1992). The Gaussian distribution of the 2003 maximum summer temperatures (curve $\mathrm{C}$ ) is the only instance in the $20^{\text {th }}$ century record of a range of summer maximum temperatures that is located entirely within that of the 2071-2100 period and with an almost identical median value. 


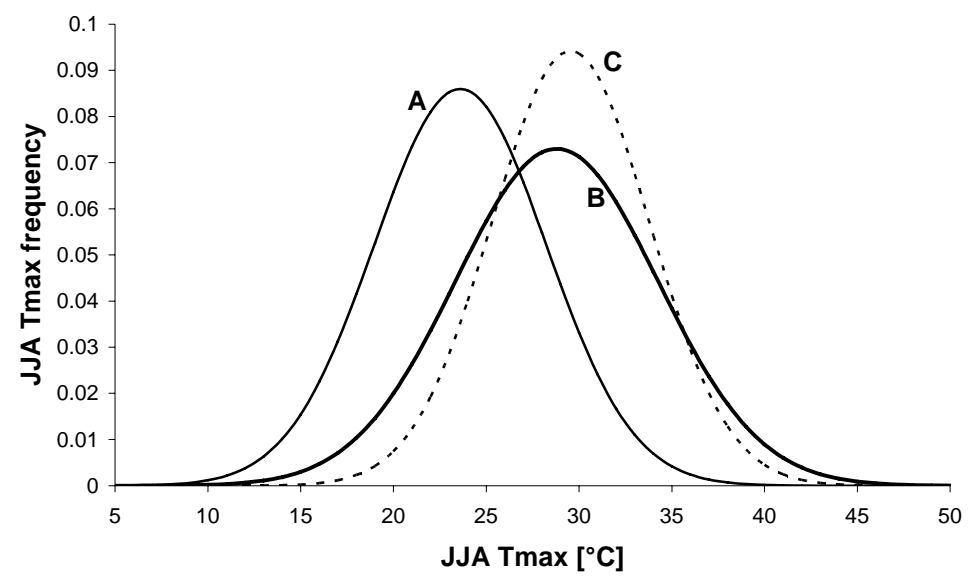

Figure 9. Gaussian distributions fitted to the mean summer maximum temperature data at Basel, Switzerland, for A) the 1961-1990 reference period; B) the 2071-2100 A-2 scenario simulation; and C) the 2003 heat wave.

\section{EXTREME EVENTS IN A CHANGING CLIMATE DURING THE $21^{\text {ST }}$ CENTURY}

A crucial question in a changing climate is the manner in which extremes of climate may change in intensity and/or frequency as conditions become warmer. Although additional heat in the atmosphere may be a necessary condition to supply energy to drive intense systems, it is by no means a sufficient condition for generating extreme events. In order to investigate the future behavior of a non-linear system such as climate, it is necessary to use 3-D numerical modeling systems applied to the global and regional scales.

The complexity and mutual inter-dependency of mountain environmental and socio-economic systems in regions such as the Alps pose significant problems for climate impacts studies (Beniston et al., 1996), particularly when dealing with extreme weather events. Even the relatively high spatial resolution of current general circulation models (GCMs) remains too low to adequately represent the orographic detail of most mountain regions. On the other hand, most impacts research requires information at fine spatial definition, where the regional details of topography or land-cover are important determinants in the response of natural and managed systems to climatic change. Since the mid-1990s, the scaling problem related to complex orography has been addressed through regional modeling techniques, such as thoses pioneered by Giorgi and Mearns (1991), and through statistical-dynamical downscaling techniques (e.g., Zorita and von Storch, 1999).

So-called "nested" approaches to regional climate simulations, whereby large-scale data or GCM outputs are used as boundary and initial conditions for regional climate model (RCM) simulations, have been applied to scenario computations for climatic change in the $21^{\text {st }}$ century (Giorgi and Mearns, 1999). The technique is applied to specific periods in time ("time slices" or "time windows") for which high-resolution simulations are undertaken. GCM results for a given period include the long-term evolution of climate prior to the particular time horizon, based on an incremental increase of greenhouse gases. The RCM focuses on a high-resolution simulation for a limited time span over a restricted geographical area. The nested modeling approach represents a trade-off between decadal- or centuryscale, high resolution simulations and coarse resolution results provided by long-term GCM integrations. Although the method has a number of drawbacks, in particular the fact that the nesting is "one-way" (i.e., the climatic forcing occurs only from the larger to the finer scales and not vice-versa), RCMs in general improve the regional detail of climate processes. This can be an advantage in areas of complex topography, where orographic precipitation may represent a significant fraction of annual or seasonal rainfall in many parts of mid-latitude mountain regions. Such improvements are related to the fact that RCM simulations capture the regional detail of such forcing elements as topography or large lakes, and the local forcing by these features on regional climate processes generally better than GCMs (Beniston, 2000).

When applied to climate change scenarios, global and regional models are powerful tools that allow an insight into the possible climate futures in response to various levels of greenhouse gas emissions and concentrations. Figure 10 shows the probable global warming rate in response to a number of emission scenarios developed by the IPCC (Nakicenovic et al., 2000). According to the scenario, the response of climate ranges from an increase in global mean temperatures of $1.4^{\circ} \mathrm{C}$ to $5.8^{\circ} \mathrm{C}$. The scenarios are based on pathways of economic and population growth, hypotheses related to technological advances, the rapidity with which the energy sector may reduce its dependency on fossil fuels, and other 
socio-economic projections related to deforestation and land-use changes, for example. Socio-economic futures are of course fraught with uncertainty, hence the range of scenarios that the IPCC has developed in order to have a physicallyconsistent set of climatic responses to future global social, demographic, and economic trends.

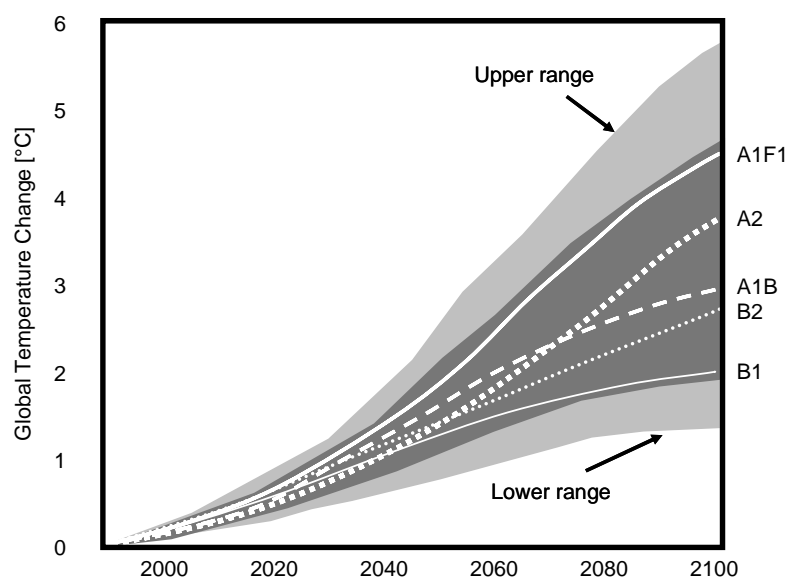

Figure 10. Global warming futures according to various greenhouse gas emission scenarios developed by the Intergovernmental Panel on Climate Change.

At the regional scale, RCM simulations undertaken in the EU-PRUDENCE project framework mentioned above suggest that, on average, Europe is likely to experience a rise in average temperatures by about $4{ }^{\circ} \mathrm{C}$ in the period 2071 2100 compared to the reference period 1961-1990, when using the IPCC Scenario A-2 for greenhouse gas emissions; this scenario represents an upper range of possible futures illustrated in Figure 10. The distribution of changes in summer maximum temperatures is given in Figure 11 (left), where a general northward migration of climatic zones leads to warming that exceeds $6^{\circ} \mathrm{C}$ from the Iberian Peninsula to SW France. The changes in the $90 \%$ quantile of maximum temperature (Figure 11, right), exhibit an asymmetric increase, i.e., the shifts in the upper extremes of summer temperatures are generally more marked than the changes in means, and can exceed $8^{\circ} \mathrm{C}$ in some parts of western and southern Europe. The change in mean summer maxima is thus accompanied almost everywhere by disproportional shifts in the extremes. This can have significant repercussions for hydrology, ecosystems, and agriculture, where extreme temperatures exert stronger controls on evaporation or desiccation, heat and water stress on plants than mean temperatures.
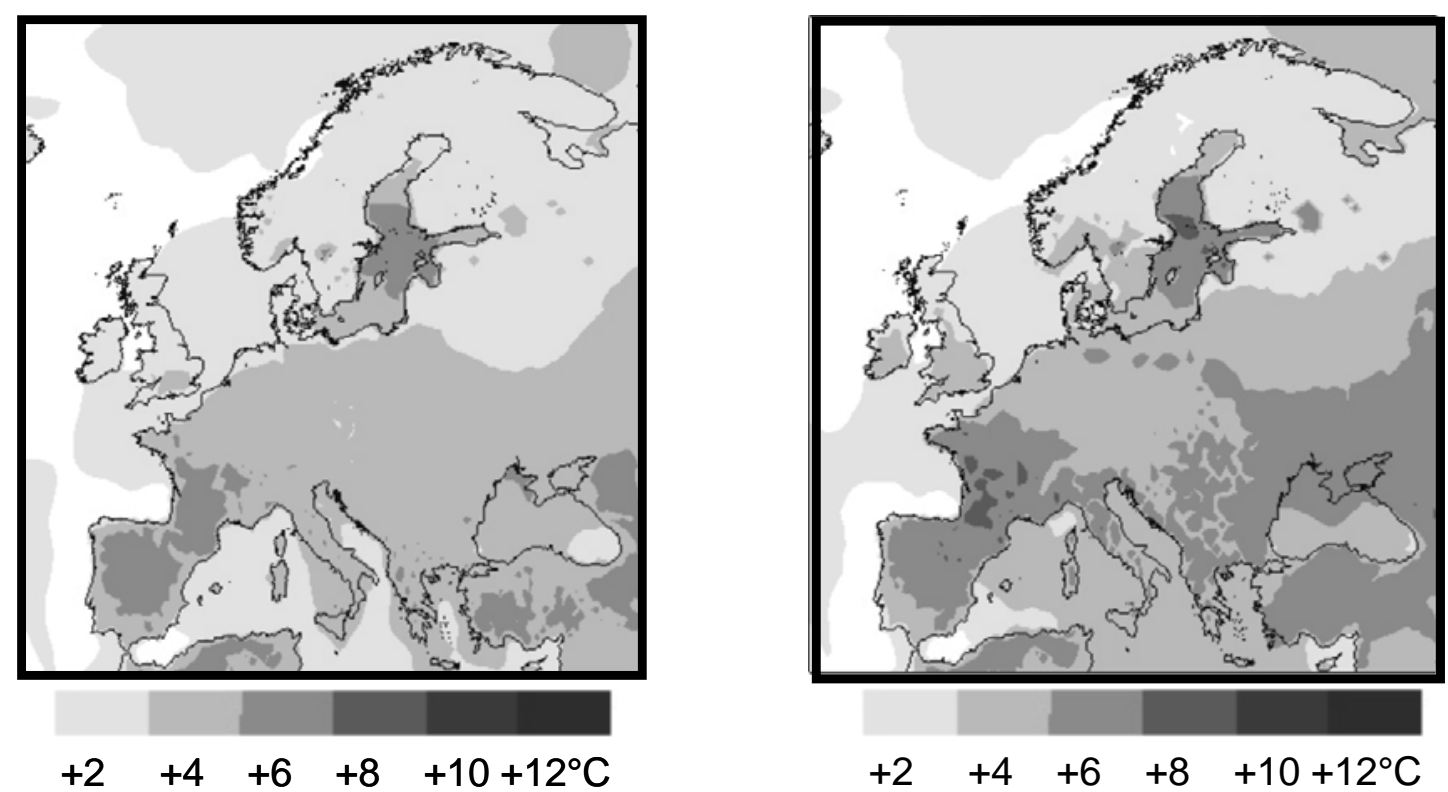

Figure 11. Left: shifts in mean summer (June, July and August) maximum temperatures in Europe between current climate (19611990 average) and future climate (2071-2100 average) for IPCC Scenario A-2; right: shifts in extreme summer temperatures above the $90 \%$ quantile between current and future climates(Figure: Courtesy B. Koffi, University of Fribourg). 
Future precipitation trends, while more problematic to simulate in climate models than temperature, nevertheless exhibits a dual trend, i.e., a general reduction in average annual precipitation, and an increase in extreme precipitation events. This has already been shown to be the probable case for much of Europe by Christensen and Christensen (2003), where as a result of much warmer summer temperatures, precipitation tends to decrease on average. On the other hand, the energy supplied by the higher temperatures is capable of triggering short-lived but very severe convective rainfall events, which in some parts of the Alps could increase by as much as $30 \%$ for a $2^{\circ} \mathrm{C}$ warming (Frei et al., 1998).

Simulations of daily precipitation over the Swiss Plateau suggest that both ends of the precipitation spectrum, i.e, very dry conditions or those associated with strong precipitation events, may increase in a warmer climate. For the lower elevations of Switzerland that the HIRHAM model covers reasonably well, average precipitation is seen to change by a very small amount. However, episodes with little or no rainfall in are projected to increase by a factor of 1.8 in the future, while the number of days with precipitation exceeding $25 \mathrm{~mm} /$ day or more is simulated to rise by a factor about $30 \%$. The tendency of a dual simultaneous increase of both low and high precipitation extremes in the mid-latitudes in a warmer climate has been reported elsewhere, notably for North America (e.g., IPCC, 2001; Trenberth, 1999).

Very preliminary results from modeling studies of extreme winter storms, based on model studies of events such as the 1990 Vivian storm (Goyette et al., 2001) or the 1999 Lothar storm (Goyette et al., 2003), suggest an increase in the frequency of strong winds originating in the Atlantic at the expense of föhn-type storms related to southerly flow across the Alps. There is a strong probability that the alpine region will experience at least one event of similar intensity to the 1999 Lothar "storm-of-the-century" by 2020. While this may not appear to be significant, it should be borne in mind that the insured infrastructure is likely to increase over the next decades, thus leading to a strong rise in damage costs in the event of such a wind storm affecting the region.

\section{CONCLUSIONS}

While changes in the long-term mean state of climate is likely to impose important constraints on numerous environmental, social, and economic systems, the most significant impacts of climatic change are likely to arise following shifts in the intensity and the frequency of extreme weather events. Insurance costs resulting from extreme weather events have been steadily rising since the $1970 \mathrm{~s}$, essentially in response to increases in population pressures in regions that are at risk, but also in part because of recent changes in the frequency and severity of certain forms of extremes.

Regions now considered safe from catastrophic wind storms, heat waves, and floods could become increasingly vulnerable in the future. Under such circumstances, the associated damage costs would become extremely high, also because the cost of infrastructure will also continue to increase. Society will face considerable challenges when faced with events such as the 2003 heat wave, for example, that are projected to become more common in the latter decades of the $21^{\text {st }}$ century. In view of the severity of the impacts that affected much of Europe throughout the summer of 2003 , such as excess deaths recorded in France, Italy, and Spain (WHO, 2003), crop failures in many of the producing countries, and strongly-reduced discharge in numerous rivers, the 2003 heat wave as a "shape of things to come" is a signal that should be given appropriate consideration by decision-makers.

It is therefore important in view of the environmental, human and economic costs exerted by extreme climatic events to address the problem of their behavior in a changing global climate, in order to develop a conceptual basis of sufficient quality to enable a quantification of their future probability of occurrence and lead to the establishment of appropriate response strategies aimed at minimizing the consequences of such events.

\section{References}

Beniston, M., 2000 : Environmental Change in Mountains and Uplands. Arnold Publishers, London, and Oxford University Press, New York, 172 pp.

Beniston, M., 2004: The 2003 heat wave in Europe: A shape of things to come? Geophys. Res. Letters, 31 , L02202

BUWAL, 2000 : Data on site: www.unece.org/trade/timber/storm/swi/degats.pdf

Christensen, J. H., and Christensen, O. B., 2003: Severe summertime flooding in Europe. Nature, 421, 805-806.

Christensen, J.H., T. Carter, F. Giorgi, PRUDENCE Employs New Methods to Assess European Climate Change, EOS, Vol. 82, p. 147, 2002

Christensen, O. B., Christensen, J. H., Machenhauer, B., and Botzet, M., 1998: Very high-resolution regional climate simulations over Scandinavia - Present climate. J. Climate, 11, 3204-3229 
Frei, C., Schär, C., Lüthi, D., and Davies, H.C., 1998: Heavy precipitation processes in a warmer climate. Geophys. Res. Lett., 25, 1431-1434

Giorgi, F., and Mearns, L.O., 1991: Approaches to the simulation of regional climate change. Rev. Geoph., 29, 191216.

Giorgi, F., and Mearns, L. O., 1999: Regional climate modeling revisited. J. Geophys. Res., 104, 6335-6352

Goyette, S., Beniston, M., Jungo, P., Caya, D., and Laprise, R., 2001: Numerical investigation of an extreme storm with the Canadian Regional Climate Model: The case study of windstorm Vivian, Switzerland, February $27,1990$. Climate Dynamics, 18, 145-168

Goyette, S., Brasseur, O., and Beniston, M., 2003: Application of a new wind gust parameterisation ; multi-scale case studies performed with the Canadian RCM. J. Geophys. Res., 108, 4374-4389

IPCC, 2001: Climate Change. The IPCC Third Assessment Report. Volumes I (Science), II (Impacts and Adaptation) and III (Mitigation Strategies). Cambridge University Press, Cambridge and New York.

Katz, R. W., and Brown, B. G., 1992: Extreme events in a changing climate: Variability is more important than averages. Climatic Change, 21, 289-302

Munich Re, 2002 : Topics, An annual review of natural catastrophes. Munich Reinsurance Company Publications, Munich, 49 pp.

Nakićenović, N., J. Alcamo, G. Davis, B. de Vries, J. Fenhann, S. Gaffin, K. Gregory, A. Grübler, T.Y. Jung, T. Kram, E.L. La Rovere, L. Michaelis, S. Mori, T. Morita, W. Pepper, H. Pitcher, L. Price, K. Raihi, A. Roehrl, H-H. Rogner, A. Sankovski, M. Schlesinger, P. Shukla, S. Smith, R. Swart, S. van Rooijen, N. Victor, Z. Dadi, 2000: IPCC Special Report on Emissions Scenarios, Cambridge University Press, Cambridge, United Kingdom and New York, NY, USA, 599 pp.

Schär, C., P.L. Vidale, D. Lüthi, C. Frei, C. Häberli, M. Liniger and C. Appenzeller, 2004: The role of increasing temperature variability in European summer heat waves. Nature, 427, 332-336

Swiss Re, 2003: Natural catastrophes and reinsurance. Swiss Reinsurance Company Publications, Zürich, 47 pp.

Trenberth, K. E., 1999: Conceptual framework for changes of extremes of the hydrological cycle with climate change. Climatic Change, 42, 327-339

Ulbrich, U., Fink, A.H., Klawa, M., and Pinto, J.G., 2000: Three extreme storms over Europe in December 1999, Weather, 56

WHO, 2003: The health impacts of 2003 summer heat-waves. Briefing note for the Delegations of the fifty-third session of the WHO (World Health Organization) Regional Committee for Europe, $12 \mathrm{pp}$.

WMO, 2003: World Meteorological Organization statement on the status of global climate in 2003. WMO publications, Geneva, 12 pp.

Zorita, E. and H. von Storch, 1999: The analog method - a simple statistical downscaling technique: comparison with more complicated methods. J. Climate 12: 2474-2489 